\title{
Colorectal cancer disparities and African Americans: Is it time to narrow the gap?
}

\author{
Kenneth Iwuji MD, Briget Hyde BS, Nkemjika Uke BS
}

\begin{abstract}
Colorectal cancer is the second most common cause of cancer death in both men and women. Although the overall incidence and mortality rates of colorectal cancer are declining, African Americans have significantly higher rates of colorectal cancer than Caucasians, and they have worse 5-year survival rates. This article reviews some of the contributing factors that lead to this racial disparity in colorectal cancer between these groups. The increase in poor health outcomes among African Americans is due to low socioeconomic standing, poor compliance, psychosocial barriers, and patient mistrust of healthcare providers and the healthcare system. Research on interventions to improve health outcomes is important to reduce the causes of these disparities.
\end{abstract}

Keywords: colorectal cancer; screening; African Americans; Blacks; health disparities; interventions; public health.

\section{INTRODUCTION}

Among the cancers that affect both men and women, colorectal cancer (CRC) is the second most common cause of cancer-related death in the United States. ${ }^{1}$ The incidence of CRC is about $30 \%$ to $40 \%$ higher in men than in women. ${ }^{2}$ It is estimated that in 2020 about 147,950 individuals will be diagnosed with CRC and 53,200 will die from CRC; 17,930 cases and 3,640 deaths will occur in people younger than 50 years. In the last decade, there has been a decline in the incidence of CRC in adults aged 50 years and older. ${ }^{3}$ According to the American Cancer Society, the decline in mortality is due to advances in treatment, changes in risk factors, and increased screening. Although the decrease is narrowing the mortality gap between African Americans and non-Hispanic Caucasians, the incidence and mortality from CRC

Corresponding author: Kenneth Iwuji Contact Information: Kenneth.iwuji@ttuhsc.edu DOI: $10.12746 /$ swrccc.v9i40.887 remains higher in African Americans, and they are diagnosed at later stages than Caucasians. This disparity is steadily increasing. ${ }^{4}$

African Americans are $38 \%$ to $43 \%$ more likely to die from CRC than Caucasians. African Americans are diagnosed late in the disease course and tend to have right-sided tumors, well differentiated tumors, ${ }^{4}$ and worse 5-year survival rates than Caucasians. In addition, African Americans are more likely to develop toxicity with 5-fluorouracil, perhaps due to their reduced dihydropyridine dehydrogenase enzyme activity. ${ }^{6}$ The later presentation of disease may be due to the lower rate of screening surveillance compared to Caucasians. ${ }^{7}$

\section{Why do African Americans have a high DISEASE BURDEN WITH COLORECTAL CANCER?}

Several factors have a role in CRC presentation in the African American community. Genetic factors, like germline mutations in the APC, MMR, and MUYTH genes, increase the risk of CRC and other types of cancers in the general population. ${ }^{8}$ KRAS mutations, somatic mutations present in some CRC cells, have 
been shown to occur more often in African Americans and are associated with advanced stages at diagnosis. ${ }^{8}$ Hereditary CRC accounts for only a small fraction of all CRCs, so it would require an extremely large sample to determine the presence of differences between races. Genetic testing to assess the presence of germline mutations in patients at increased risk of CRC or somatic mutations in patients with CRC can help guide the course of future management.

Diet is another factor that affects the gut microbiome and in turn may impact the risk for CRC. For example, the incidence of CRC in African Americans is 60 per 100,000 per year, but in South Africans it is 5 per 100,000 per year. ${ }^{7}$ Diet may have a role in this discrepancy since the Western diet consists of foods with high fat, high protein, and low fiber, whereas the typical South African diet is low in fats and protein and high in fiber. A diet swap study between African Americans and South Africans showed an increase in sulfidogenic bacteria in South Africans and a reverse relationship in African Americans. ${ }^{9} \mathrm{~A}$ gut biome analysis between African Americans and Caucasians also showed the presence of more sulfidogenic bacteria in African Americans than Caucasians. ${ }^{10}$ Sulfidogenic bacteria have a higher rate of bile acid deconjugation, and bile acids are hypothesized to be carcinogenic. The diet swap study also showed increased gut epithelial proliferation in African Americans, which can be a marker for cancer development. ${ }^{8}$

Colorectal cancer screening with methods, such as fecal occult blood test, fecal immunohistochemistry test, sigmoidoscopy, and colonoscopy in individuals above 50 , has been instrumental in reducing the incidence of CRC. However, African Americans still have a higher CRC mortality and morbidity than their White counterparts. ${ }^{11}$ Numerous factors have a role in this disparity, including low socioeconomic status, low health literacy, insurance status or degree of coverage by insurance plan,,$^{15}$ lower quality of care, and poor physician-patient communication that results in decreased compliance and follow-up. There are also strong psychosocial aspects such as mistrust of healthcare workers, perceived altered masculinity associated with invasive rectal procedures, underestimation of CRC risks, and fear of experimentation. ${ }^{11}$
These are multifactorial problems and, therefore, will require a multifactorial approach to resolve.

\section{HOW CAN THESE COLORECTAL-RELATED HEALTH DISPARITIES BE MINIMIZED?}

The American College of Gastroenterologists has recommended that $\mathrm{CRC}$ screening in African Americans should be started at age 45 , as opposed to 50 for the general population. However, the U.S. Preventive Services Task Force still recommends screening at 50 due to the lack of evidence supporting the effectiveness of earlier screening in African Americans. ${ }^{5}$ The effectiveness of screening is also heavily dependent on compliance and follow-up of patients with health care providers. One of the reasons for poor follow-up from African American patients is the invasiveness of a colonoscopy. This includes the fear of being in a hospital setting, pain from the procedure, and perceived diminished masculinity during a colonoscopy. ${ }^{14}$ The fear of invasive procedures is also experienced in other forms of cancer screening such as prostate cancer, in which African American men are more likely to report their dissatisfaction with a digital rectal exam than Caucasian men. ${ }^{15}$ Lessinvasive, stool-based screening measures like fecal occult blood test or fecal immunochemical test may increase screening completion in African Americans compared to invasive procedures. ${ }^{15}$ Despite noninvasive tests, there is still an issue of non-compliance; African Americans are $10 \%$ less likely to follow-up after a positive screening test than Caucasians. ${ }^{5}$

Programs like the Screening Colonoscopies for People Everywhere in South Carolina (SCOPE $\mathrm{SC})$, done on Caucasian and African American noninsured patients, reported an $85 \%$ completion rate in patients when health navigators were trained in educating patients on bowel preparations and referral details regarding CRC screening. ${ }^{11}$ Similar programs also provide additional assistance with scheduling appointments, sending reminders, and rescheduling canceled appointments. Interventions that make the communication between patients and their primary care providers (PCPs) more effective can also reduce African Americans' mistrust of healthcare providers and increase compliance. ${ }^{5}$ The use health navigators 
or educators, ${ }^{5,12}$ as mentioned earlier, can be an invaluable tool to ensure patients follow-up with their required screening. There have also been technologybased interventions that aim to increase awareness and compliance and to educate the African American community about CRC through methods like phone calls, text messages, emails, websites, mobile apps, and targeted-entertainment education aids, which show promise but still provide a challenge to patients at risk who are often older, not technologically savvy, or lack the devices to access these kinds of communication. ${ }^{5,12,13}$

Changes to address these issues require a collective effort from African American communities, local public health departments, insurance companies, medical communities, and state and federal governments. Proper, culturally tailored, and age-appropriate education is a good start to laying foundations that address the negative perceptions of CRC screening. This requires the help of skilled physicians, healthcare workers, and mental health specialists to create a space for the African American community, especially men, to discuss their concerns regarding the screening process. Plans should involve increasing the availability of CRC screening resources, such as government loans/grants that make colonoscopies more affordable or free to the underserved and low socioeconomic status communities. Reporting rates of CRC screening in these communities can also provide a way of assessing the effectiveness of current interventional methods.

Culturally based education, especially with PCPs, oncologists, and gastroenterologists, can alleviate some of these problems. Primary care physicians are at the front line of this problem, since they perform most of the guideline directed screenings and provide referrals as needed. If patients are made aware of the high incidence and mortality of CRC among African Americans, they are more likely to spend time discussing these diseases with their PCPs. Complete colonoscopy should also be encouraged to ensure that the right colon is well inspected. Oncologists treating African Americans with CRC need to also be aware of the late presentation with advanced disease seen in this racial group.

\section{ConcLusion}

The increased incidence, mortality rates, and disparities of CRC between African Americans and Caucasians show the need for more attention and intervention. Suggested ways to mitigate this disparity include decreasing the screening age, raising awareness, and promoting effective communication and education between physicians and patients to increase patient compliance and follow-up after diagnosis, and increasing accessibility to programs that provide assistance with the CRC screening process. More effort should be made in studying effective and long-lasting interventions.

Article citation: Iwuji K, Hyde B, Uke N. Colorectal cancer disparities and African Americans: Is it time to narrow the gap? The Southwest Respiratory and Critical Care Chronicles 2021;9(40):27-30

From: Department of Internal Medicine, Texas Tech University Health Sciences Center, Lubbock, Texas

Submitted: 4/29/2021

Accepted: $7 / 3 / 2021$

Reviewer: Catherine Jones MD

Conflicts of interest: none

This work is licensed under a Creative Commons Attribution-ShareAlike 4.0 International License.

\section{REFERENCES}

1. Joseph DA, King JB, Miller JW, et al. Centers for Disease Control and Prevention (CDC). Prevalence of colorectal cancer screening among adults-Behavioral Risk Factor Surveillance System, United States, 2010. MMWR Suppl 2012 Jun 15;61(2):51-6.

2. American Cancer Society, Colorectal Cancer Facts and Figures 2017-2019, Atlanta, GA: American Cancer Society, 2017. Accessed December 13, 2020.

3. Siegel R L, Miller K D, Goding Sauer A, et al. Colorectal cancer statistics, 2020. CA: Cancer J Clinicians 2020 May;70(3):145-164.

4. Berry J, Bumpers K, Ogunlade V, et al. Examining racial disparities in colorectal cancer care. J Psychosocial Oncol 2009;27(1):59-83. 
5. Kwaan MR, Jones-Webb R. Colorectal cancer screening in black men: recommendations for best practices. American $\mathrm{J}$ Preventive Medicine 2018 Nov 1;55(5):S95-102.

6. Mattison L K, Fourie J, Desmond R A, et al. Increased prevalence of dihydropyrimidine dehydrogenase deficiency in African-Americans compared with Caucasians. Clinical Cancer Research 2006. https://clincancerres.aacrjournals.org/ content/12/18/5491.

7. Dimou A, Syrigos KN, Saif MW. Disparities in colorectal cancer in African-Americans vs Whites: before and after diagnosis. World J Gastroenterol 2009 Aug 14;15(30): 3734-43.

8. Augustus GJ, Ellis NA. Colorectal cancer disparity in African Americans: risk factors and carcinogenic mechanisms. Am J Pathol 2018 Feb;188(2):291-303.

9. O'Keefe SJD, Li JV, Lahti L. Fat, fiber and cancer risk in African Americans and rural Africans. Nat Commun 2015 Apr 28; 6:6342. doi: 10.1038/ncomms 7342

10. Yazici C, Wolf PG, Kim H, et al. Race-dependent association of sulfidogenic bacteria with colorectal cancer. Gut 2017 Nov 1;66(11):1983-94.
11. Adams LB, Richmond J, Corbie-Smith G, et al. Medical mistrust and colorectal cancer screening among African Americans. J Community Health 2017 Oct;42(5):1044-1061.

12. Xirasagar S, Li YJ, Burch JB. Reducing colorectal cancer incidence and disparities: performance and outcomes of a screening colonoscopy program in South Carolina. Advances Public Health 2014 Jan 1;2014. https://doi.org/10.1155/ 2014/787282

13. Brittain K, Kamp K, Cassandras C, et al. A mobile app to increase informed decisions about colorectal cancer screening among African American and Caucasian women: a pilot study. Gastroenterology nursing: the official journal of the Society of Gastroenterology Nurses and Associates. 2018 Jan;41(1):14.

14. Hoffman AS, Lowenstein LM, Kamath GR, et al. An entertainment education colorectal cancer screening decision aid for African American patients: A randomized controlled trial. Cancer 2017 Apr 15;123(8):1401-8.

15. Bromley, Erica $\mathrm{G}$ et al. Explaining persistent under-use of colonoscopic cancer screening in African Americans: a systematic review. Preventive Medicine 2015;71:40-8. 